AFTER THE DELUGE: DO FIXED

EXCHANGE RATES ALLOW INTER-

TEMPORAL VOLATILITY TRADEOFFS?

Andrew K. Rose

Working Paper No. 5219

\author{
NATIONAL BUREAU OF ECONOMIC RESEARCH \\ 1050 Massachusetts Avenue \\ Cambridge, MA 02138 \\ August 1995
}

For hospitality during the course of this research, I thank the International Monetary Fund, the Bank of Israel, and the Institute for International Economic Studies. I also thank Robert Flood for encouragement and discussions. The STATA 4.0 programs and data used in this analysis are available for a year following publication, upon receipt of a self-addressed stamped mailer with a 3.5" formatted high-density diskette. This paper is part of NBER's research program in International Finance and Macroeconomics. Any opinions expressed are those of the author and not those of the National Bureau of Economic Research.

() 1995 by Andrew K. Rose. All rights reserved. Short sections of text, not to exceed two paragraphs, may be quoted without explicit permission provided that full credit, including $\odot$ notice, is given to the source. 


\title{
AFTER THE DELUGE: DO FIXED \\ EXCHANGE RATES ALLOW INTER- TEMPORAL VOLATILITY TRADEOFFS?
}

\begin{abstract}
This paper addresses the issue of whether regimes of fixed exchange rates are a mechanism for shifting volatility inter-temporally. Using a panel of data covering twenty industrialized countries from 1959 through 1993, I examine the volatilities of a host of real and monetary variables. Graphical and statistical examination of the periods around 33 flotations and 81 devaluations reveals little evidence of significant increases in volatility following these events.
\end{abstract}

Andrew K. Rose

Haas School of Business

University of California, Berkeley

Berkeley, CA 94720-1900

and NBER 


\section{I: Introduction and Motivation}

Flood and Rose (1995) examined monetary models of exchange rate determination across different exchange rate regimes. They asked the question: "Is the lower exchange rate volatility induced by regimes of fixed exchange rates associated with systematically different volatility elsewhere in the economy?" They used fundamentals dictated by a variety of theoretical models, and found that different exchange rate regimes had broadly similar volatility of fundamentals, but different exchange rate volatility. That is, governments who managed their exchange rates experienced lower exchange rate volatility without suffering higher volatility in e.g., money or output. Thus, there is remarkably little evidence of an inter-sectoral "volatility tradeoff"; historically, squeezing volatility out of the foreign exchange market does not appear to have induced higher volatility in other sectors of the economy.'

This is a potentially important finding. If exchange rate volatility is welfarereducing and can be reduced without causing harmful spillovers to other sectors of the economy, the case for fixed exchange rates becomes stronger.

This paper continues the Flood-Rose line of reasoning. Instead of looking for an inter-sectoral volatility tradeoff, I search for an inter-temporal volatility tradeoff. The theoretical arguments for inter-sectoral volatility substitution are much stronger than those for a comparable inter-temporal tradeoff. However, the latter appears to be part of the informal folk wisdom concerning the drawbacks of fixed exchange rates. In particular, it is sometimes informally asserted that fixed exchange rates allow governments to "bottle

1 Flood and Rose (1993) compared a number of bilateral exchange rates vis-a-vis the United States before and after 1973. Rose (1993) is the cross-sectional analogue to this time-series work, comparing countries which were fixed and floating vis-a-vis Germany; similar results were found. 
up" pressure, but only temporarily. Fixed exchange rate regimes eventually collapse, and the pressure is then released. Thus, the story goes, governments have only shifted underlying volatility from one period of time to another. This paper examines this line of reasoning empirically.

The theoretical literature does not presently contain models with strong predictions about where inter-temporal volatility tradeoffs should be found. Thus my search is necessarily broad. I use a panel data set, covering over twenty industrialized countries from 1959 through 1993. I search for systematic volatility increases in twenty-five different macroeconomic variables, covering an array of monetary, capital, labor, real, and international markets. I look separately at both flotations and devaluations of fixed exchange rates, and search for volatility shifts following either event. In each case, I compare the volatility of the variable up to three years before and after the actual exchange market event, using both graphical and statistical techniques.

Despite the wide-ranging nature of my search, I am not able to find strong evidence of an inter-temporal volatility tradeoff. When previously fixed exchange rates are floated, exports and the current account become more somewhat more variable, as do a variety of asset prices (including the exchange rate!). But very few other volatility shifts are apparent. Indeed, the hypothesis of unchanged volatility around flotations is a very good first approximation for monetary, labor, and real macroeconomic variables. The same characterization holds true for devaluations.

I conclude that there is little evidence that fixed exchange rates act as a device which effectively shifts unavoidable macroeconomic volatility over time. This is consistent 
with the Flood-Rose finding that fixed exchange rates do not shift volatility across different sectors of the economy. Empirically, exchange rate volatility has historically been reduced without detectable volatility consequences, perhaps because it is the result of bubbles or "noise-trading".

In section II, I discuss the theoretical framework for my empirical inquiry; the data set is discussed in the next section. Section IV contains the meat of the paper. It is a graphical examination of volatility around different periods of exchange rate flotations and devaluations of fixed exchange rates. Section $\mathrm{V}$ contains some statistical tests for systematic shifts in volatility, while the paper concludes in section VI.

\section{II: A Theoretical Framework}

I use a simple standard monetary model to frame my theoretical discussion, relying on Flood and Rose (1995). ${ }^{2}$

The generic monetary exchange rate model begins with a structural money-market equilibrium condition, expressed in natural logarithms as:

$$
m_{t}-p_{t}=\beta y_{t}-\alpha i_{t}+\varepsilon_{t}
$$

where: $m_{t}$ denotes the (log of the) stock of money at time $t ; p$ denotes the price level; $y$ denotes real income, which proxies for the demand for money-financed real transactions; i

2 The classic speculative attack models such as Krugman (1979) and Flood and Garber (1984) do not predict inter-temporal volatility tradeoffs resulting from fixed exchange rate regimes. Flood and Hodrick (1986) examine a sticky-price monetary model and show that conditional real output volatility in the period immediately preceding an exchange rate flotation may be either higher or lower than subsequent output volatility. 
denotes the nominal interest rate, the opportunity cost of holding money; $\varepsilon$ denotes a wellbehaved shock to money demand; and $\alpha$ and $\beta$ are structural parameters.

Assuming that there is a comparable equation for the foreign country, and that domestic and foreign elasticities are equal, by subtracting the foreign analogue from (1) and solving for the price terms, one arrives at:

$$
\left(p-p^{*}\right)_{t}=\left(m-m^{*}\right)_{t}-\beta\left(y-y^{*}\right)_{t}+\alpha\left(i-i^{*}\right)_{t}-\left(\varepsilon-\varepsilon^{*}\right)_{t}
$$

If prices are perfectly flexible, then purchasing power parity holds, at least up to a disturbance:

$$
\left(p-p^{*}\right)_{t}=e_{t}+v_{t}
$$

where: e denotes the domestic price of a unit of foreign exchange; and $v$ is a stationary disturbance. ${ }^{3}$ Substituting this equation into (2), one can solve for the exchange rate:

$$
e_{t}=\left(m-m^{*}\right)_{t}-\beta\left(y-y^{*}\right)_{t}+\alpha\left(i-i^{*}\right)_{t}-\left(\varepsilon-\varepsilon^{*}\right)_{t}-v_{t}
$$

The logic of this model is that exchange rate volatility is a function of shocks striking domestic and foreign output and money markets (as well as disturbances to purchasing power parity, which are presumably more sluggish). At a point in time, one can look across foreign exchange, money, and output markets to search for volatility tradeoffs. In the analysis below, I look at these markets across time.

The model points particularly to (differences between domestic and foreign values of) money, output and interest rates. In my empirical work, I look at all of these. The

\footnotetext{
${ }^{3}$ One can also use a model of sticky prices in place of this assumption without dramatically changing the results, as shown by Flood and Rose (1993).
} 
model does not state precisely which particular variable is the best proxy for $\mathrm{m}, \mathrm{y}$, and $\mathrm{I}$.

For this reason, I examine a variety of potential measures of money (I use domestic credit, M1 and M2), transactions demand (I use real industrial production, employment and real GDP) and the opportunity cost of holding money (I use interest rates, bond rates, and stock prices). I also look at different versions of exchange rate "fundamentals", i.e., [(m$\left.\left.m^{*}\right)_{t}-\left(y-y^{*}\right)_{l}\right]$, setting $\beta=1$.

The model outlined above relies upon purchasing power parity holding, at least up to a disturbance. One can also use a model of sticky prices in place of equation (3), as shown by Flood and Rose (1995). In this case, one gets additional regressors in the analogous solution to (4), such as expected exchange rate depreciation, inflation and real interest rates. The potential determinants of these expectations constitute an additional set of variables to examine. For this reason, I add a variety of external, labor market, and real variables to my analysis.

\section{III: The Data Set}

The data set I employ is a quarterly panel, spanning 1959 through 1993 for twenty-one industrial countries. ${ }^{4}$ Macroeconomic and financial data are mostly taken from the International Monetary Fund's International Financial Statistics (IFS). The data have been checked for transcription and other errors and corrected.

The empirical analysis requires the choice of a "center-country" against which others are measured. I use Germany, so that the exchange rate is the price of a

\footnotetext{
${ }^{4}$ Specifically: USA; UK; Austria; Belgium; Denmark; France; Italy; Netherlands; Norway; Sweden; Switzerland; Canada; Japan; Finland; Greece; Ireland; Portugal; Spain; and Australia; along with the center country, Germany.
} 
Deutschemark. This is a logical choice, since the DM was neither devalued nor floated out of weakness during the sample. For most purposes these variables are transformed into differential percentage changes by taking differences between domestic and German annualized first-differences of natural logarithms, multiplied by $100 .^{5}$

I use the following variables: exports and imports (both measured in dollars, IFS lines $70 \mathrm{~d}$ and $71 \mathrm{~d}$ respectively); the current account (line 77a.d, converted to domestic currency) measured as a percentage of nominal GDP (frequently line 99a); total non-gold international reserves (line 1ld); domestic credit (line 32); M1 (line 34); M2 (line 35+ M1); the central government budget position (line 80), also converted to a percentage of nominal GDP; short-term interest rates (money market rates [line 60b] where possible, discount rates otherwise [line 60]); long-term government bond yields (line 61); a nominal stock market index (line 62, which sets 1990=100); the CPI (line 64); an index of industrial production (line 66i); and real GDP (usually line 99a.r). I also use the real effective exchange rate (line reu, which uses normalized relative unit labor costs), though this variable is only available from 1975 (higher values indicate real appreciation, and the index is set such that $1990=100$ ). Data on: the business sector wage rate; the unemployment rate; total employment; investment; and inventory growth; were drawn from the OECD's Main Economic Indicators.

5 The real effective exchange rate is left unchanged; current account and budget deficits (both expressed as fractions of GDP) are left as differentials between domestic and German levels; interest rates, bond rates, stock prices indices, and unemployment rates are also expressed as differentials between domestic and German levels. 
Finally, I used the IMF's annual report on Exchange Arrangements and Exchange Restrictions (EAER) volumes to compile a list of officially declared flotations and devaluations. $^{6}$

\section{IV: A Graphical Search for Rising Volatility At Flotations and Devaluations}

Any dramatic increase in macroeconomic volatility of economic consequence which occurs at the time of exchange rate flotations or devaluations should be immediately apparent in the data. Thus, my search for this shift relies in part on a graphical examination of the data. ${ }^{7}$

Figure 1 provides evidence on the volatility of a host of macroeconomic variables in the periods around the 33 flotations which $I$ identified (Figure 2 is the analogue for the 81 devaluations). It contains twenty-five "small multiple" time-series panels. Each of these small multiples portrays a four-standard deviation band for the behavior of a single variable for the twelve quarters preceding and following flotations (the time of the actual flotation is marked with a vertical bar); these panels can be interpreted as "event studies". The lines graphed are the plus/minus two standard deviation bands, adjusted for the mean of the sample (the statistics are computed from the unweighted cross-sections). Although there are 33 flotations in the sample, the number of observations than underlies any individual point in any individual panel may be lower because of missing data. ${ }^{8}$ In this

6 These events occur when the country officially decides to float or devalue its currency against its chosen center country or basket; this need not be Germany.

7 Eichengreen et. al. (1995) use similar graphical techniques to search for antecedents and consequents of a variety of different episodes of exchange market turbulence.

8 Making the panels cross-comparable would involve the sacrifice of many observations and much precision. 
sense, the samples are not directly comparable across panels. ${ }^{9}$ If the flotations are independent, then the four-standard band is approximately a $95 \%$ confidence interval. ${ }^{10}$

To illustrate, the top-left panel shows the behavior of the real effective exchange rate, beginning three years before the actual flotation, continuing through the actual flotation (marked) in the center of the graph, and ending three years after the flotation. It is centered around 100 (the base value) before the flotation, with a narrow confidence interval. After the flotation (and indeed in the period immediately preceding it as well) the $4 \sigma$ band width increases dramatically; the average value also drops. This indicates, unsurprisingly, that flotations are followed by both real depreciation and an increased cross-sectional spread of real exchange rates.

The variables portrayed in the figures are the $4 \sigma$ bands for the raw data series (typically transformed into differentials between domestic and German percentage changes, as discussed above), with a few additions. I add the velocity of M1 (三Nominal GDP/M1) and the "fundamentals" dictated by a flexible-price monetary model with unit income-elasticity for M1 (=M1-Real GDP), M2, and domestic credit.

The null hypothesis of interest is a significant increase in volatility approximately coincident with an exchange rate flotation or devaluation. Such an increase in volatility would be manifest in the figures as a widening of the $+/-2$ standard deviations bands after flotations, that is, towards the right side of the panels.

\footnotetext{
9 There is no "exclusion windowing"; thus, there is no guarantee that the exchange rate will not be fixed and re-floated within the three-year sample (as occurred with the French Franc during the Common Margins Agreement or "snake").

10 There is no guarantee that the sample of flotations or devaluations is "large" in the statistical sense, since both of these events tend to be grouped irregularly by both time and country, and hence are not clearly independent.
} 
In fact, remarkably little is actually observed at the time of exchange rate flotations. As stated above, the (real effective) exchange rate becomes more volatile after flotations; correspondingly, reserves stabilize. Asset prices become somewhat more volatile, as is apparent from the behavior of short interest rates, long-term bond rates, and the stock market. However the increases in volatility seem to be small. There is also some evidence of moderately higher volatility in the dollar value of exports, though this is not reflected in the behavior of either dollar imports or the current account. However, most of the variables exhibit essentially no signs of increased volatility: domestic credit, M1 and M2, and the corresponding monetary "fundamentals"; the government budget deficit; price and wage inflation; unemployment and employment; the growth rates of industrial production, investment, and inventories; and real GDP growth. With the exception of the exchange rate, it is reasonable to characterize the data as showing essentially no increase in volatility after flotations.

Devaluations look quite similar, as is clear from Figure 2. There is no increase in exchange rate volatility, which seems reasonable. But there are few dramatic increases in macroeconomic volatility which coincide with devaluations. There are few manifestations of increased volatility from: the external accounts; monetary and fiscal variables; asset prices; labor markets; or real variables.

Succinctly, there is scanty evidence that periods which follow exchange rate flotations and devaluations feature higher volatility elsewhere in the economy. That is, there is little evidence that fixed exchange rates allow governments to "bottle up pressure" in the economy temporarily which is then "released" after a speculative attack. 


\section{V: Some Statistical Analysis}

Section IV is informal, relying on "ocular analysis" rather than carefully-posed statistical tests. It is also cross-sectional: the analysis looks across different episodes of exchange rate flotation or devaluation and asks whether there are shifts in the (first- or) second-moments of the distributions of different variables. One can also ask a related time-series question, namely whether the volatility of a given macroeconomic variable changed at the time of flotations or devaluations. In this section of the paper, I pursue more rigorous statistical tests which focus on the time-series behavior of individual variables.

I test the hypothesis that the standard deviation of a given variable in the year which immediately precedes the flotation or devaluation, equals the standard deviation in the year immediately following the event. I choose a one-year period so as to focus on a period of interest in which the exchange rate event can be treated as a major economic shock. ${ }^{11}$ It is necessary to pool observations, in order to have sufficient degrees of freedom.

Table I tabulates estimates of standard deviations in the year after (" $\sigma$ After") and before (" $\sigma$ Before") both flotations and devaluations. In addition, the probability value for a two-sided asymptotic F-test of the null hypothesis of equal standard deviations is tabulated. Small p-values are inconsistent with the null hypothesis; they represent evidence of volatility which varies significantly before and after the event. But not all of

\footnotetext{
11 A longer window allows for the effects of other events to impinge, thereby blurring the results; a shorter window may not allow for the full effects of any "built-up pressure" to be released.
} 
these rejections indicate higher volatility after the flotation or devaluation; reserves are significantly less volatile after flotations, for instance. I highlight significant evidence of higher post-event volatility accordingly in bold.

The results in Table I confirm the visual impression left by the figures. There is evidence of higher post-flotation volatility for exports, the current account, the bond rate, and employment. But the evidence from nearly all of the variables is consistent with the hypothesis that macroeconomic volatility does not change at flotations. The same is basically true of devaluations: the stock market, credit, and the corresponding "fundamentals". But the opposite is true of the current account, M1, employment, industrial production, and real GDP. And the majority of the variables show few signs of time-varying standard deviations. ${ }^{12}$

To summarize, statistical tests confirm the sense left by the graphics, namely that exchange rate flotations and devaluations are not associated with consistently higher volatility in the macroeconomy.

\section{VI: A Conclusion}

Freely floating exchange rates are more volatile than exchange rates which are fixed within bands by governments. Why?

\footnotetext{
12 One can also compare the time-series volatility of variables before and after individual devaluations and flotations without pooling data across different events. This is a more difficult exercise because of sample sizes: the three years before (or after) an event yield only twelve quarterly observations which are unlikely to be independent, and may be affected by a host of non-event related phenomena. With these caveats in mind, I compared the volatility of the real variables in the three years before and after events. About $20 \%(30 \%)$ of the tests are inconsistent at the $1 \%(5 \%)$ significance level with the null hypothesis of equal volatility before and after flotations; but a seventh of these show higher pre-event volatility. About $13 \%(25 \%)$ of the tests are inconsistent at the $1 \%(5 \%)$ significance level with the null hypothesis of equal volatility before and after devaluations; but over half of these show higher pre-event volatility.
} 
One explanation states that the underlying source of this exchange rate volatility is a set of shocks which would otherwise impinge on the macroeconomy. In this case, flexible exchange rates make sense; it is easier for the economy to deal with volatility in foreign exchange markets than in labor or output markets. Similarly, there may be good and bad times to deal with the underlying volatility, and transferring volatility from one period of time to another (by appropriate choice of the exchange rate regime) may be a reasonable policy. But the basic volatility cannot be eliminated, only transferred to a locus of the economy where it can be dealt with at low cost.

An entirely different conjecture is that volatility in foreign exchange markets is just noise, and can be eliminated with few costs to the macroeconomy.

In this paper, I have searched for signs that volatility is transferred over time from periods of fixed exchange rates to the periods after the regime breaks down. I have found negligible evidence of such an inter-temporal volatility substitution. It is more accurate to state that fixed exchange rates reduce exchange rate volatility than to state that they are mechanism for shifting the underlying volatility over time. This nudges one towards the view that floating rate volatility is non-fundamental, and can be eliminated with few macroeconomic costs by regimes of fixed rates. 


\section{References}

Eichengreen, Barry, Andrew K. Rose and Charles Wyplosz (1995) "Exchange Market Mayhem" Economic Policy forthcoming.

Flood, Robert P. and Peter Garber (1984) “Collapsing Exchange Rate Regimes" Journal of International Economics 17, 1-14.

Flood, Robert P. and Robert J. Hodrick (1986) "Real Aspects of Exchange Rate Regime Choice with Collapsing Fixed Rates" Journal of International Economics 21, 215-232.

Flood, Robert P. and Andrew K. Rose (1995) "Fixing Exchange Rates" forthcoming Journal of Monetary Economics and NBER WP \#4503.

Krugman, Paul (1979) “A Model of Balance of Payments Crises” Journal of Money, Credit, and Banking 11, 311-325.

Rose, Andrew K. (1993) "Are Exchange Rates Macroeconomic Phenomena?", Federal Reserve Bank of San Francisco Economic Review. 
Table I: Volatility Statistics Around Exchange Rate Flotations and Devaluations

\begin{tabular}{|c|c|c|c|c|c|c|}
\hline & Flotations & -------- & -------------> & Deval'ns & -------------. & ------------> \\
\hline & $\sigma$ After & $\sigma$ Before & P-value & $\sigma$ After & $\sigma$ Before & P-value \\
\hline $\begin{array}{l}\text { Real Eff } \\
\text { FX Rate }\end{array}$ & 13.2 & 8.8 & .06 & 14.9 & 15.6 & .60 \\
\hline Exports & 12.4 & 8.5 & .00 & 13.2 & 13.3 & .85 \\
\hline Imports & 18.3 & 16.2 & .20 & 10.7 & 10.7 & .98 \\
\hline C/Acc & 4.8 & 3.6 & .00 & 3.6 & 4.5 & .00 \\
\hline Reserves & 38.9 & 51.6 & .00 & 39.5 & 46.7 & .01 \\
\hline Credit & 19.6 & 21.6 & .30 & 15.5 & 13.1 & .01 \\
\hline M1 & 8.9 & 7.2 & .03 & 6.5 & 8.1 & .00 \\
\hline M2 & 8.8 & 8.2 & .46 & 6.1 & 6.9 & .07 \\
\hline Velocity & 7.2 & 8.2 & .17 & 6.2 & 6.8 & .15 \\
\hline $\begin{array}{l}\text { Gov't } \\
\text { Budget }\end{array}$ & 3.9 & 4.0 & .82 & 4.9 & 4.9 & .94 \\
\hline $\begin{array}{l}\text { Credit } \\
\text { Fund'1 } \\
\end{array}$ & 19.9 & 21.4 & .45 & 15.6 & 13.1 & .01 \\
\hline M1 Fund'l & 8.8 & 7.6 & .12 & 6.7 & 8.1 & .01 \\
\hline M2 Fund'l & 9.9 & 8.6 & .16 & 6.7 & 7.1 & .36 \\
\hline $\begin{array}{l}\text { Interest } \\
\text { Rate }\end{array}$ & 5.8 & 4.9 & .06 & 4.2 & 3.8 & .10 \\
\hline Bond Rate & 3.9 & 2.6 & .00 & 3.4 & 3.2 & .37 \\
\hline $\begin{array}{l}\text { Stock } \\
\text { Index }\end{array}$ & 18.4 & 15.3 & .07 & 14.7 & 10.3 & .00 \\
\hline $\begin{array}{l}\text { CPI } \\
\text { Inflation }\end{array}$ & 5.5 & 5.1 & .48 & 4.3 & 3.8 & .07 \\
\hline Wages & 5.5 & 5.4 & .94 & 5.1 & 4.7 & .24 \\
\hline $\begin{array}{l}\text { Unemp. } \\
\text { Rate } \\
\end{array}$ & 3.8 & 3.2 & .07 & 4.8 & 4.3 & .16 \\
\hline Employ't & 1.5 & 1.1 & .00 & 1.5 & 1.8 & .01 \\
\hline Ind'l Prod. & 5.9 & 5.2 & .22 & 4.5 & 5.8 & .00 \\
\hline Investment & 17.9 & 17.2 & .69 & 12.1 & 14.9 & .00 \\
\hline Inventory & 184. & 142. & .10 & 145. & 131. & .59 \\
\hline Real GDP & 3.6 & 3.2 & .26 & 2.7 & 3.3 & .00 \\
\hline $\begin{array}{l}\text { Nominal } \\
\text { GDP }\end{array}$ & 5.5 & 5.7 & .62 & 5.0 & 5.3 & .49 \\
\hline
\end{tabular}

" $\sigma_{\text {Before }}$ " $\left(\sigma_{\text {Ater }}\right)$ denotes the estimated standard deviation from a sampled of pooled observations during the year preceding (following) the event. Unless explicitly noted, all variables are the differences (in percentage rates of change) between domestic and German values. "P-value" denotes the probability value of the test statistic for a 2-sided test of the null hypothesis of $\sigma_{\text {Before }}=\sigma_{\text {After; }}$, low values indicate that the null hypothesis is rejected with high probability; bold values denote higher post-event volatility at the .05 level. 
Domestic Value minus German Value

Industrial Country Panel, 1959-1993. Samples not Comparable.

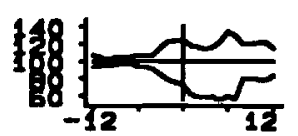

Real Eff FX Rate

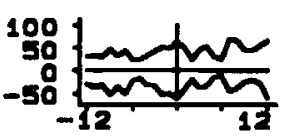

Credit, chg

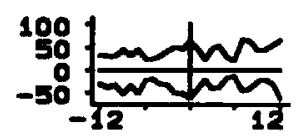

Credit Fund'1, Chg

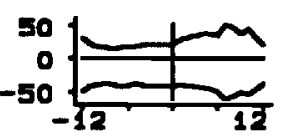

Stock Index

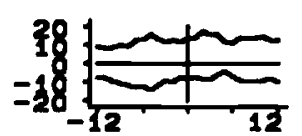

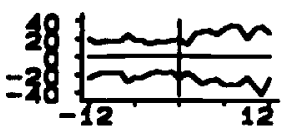

S Exports, Chg

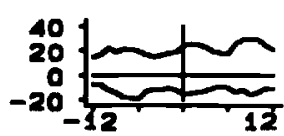

M1. Chg

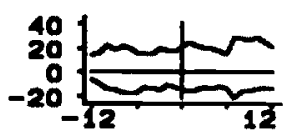

M1 Fund'l, Chg

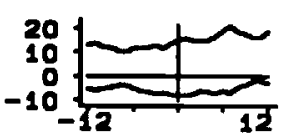

CPI Inflation

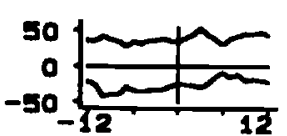

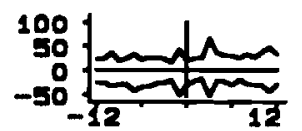

$s$ Imports, chg

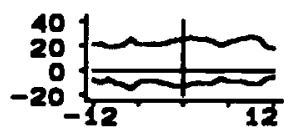

M2, Chg

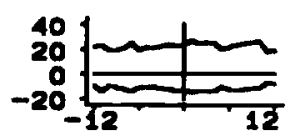

M2 Fund'l, chg

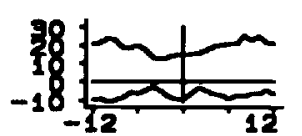

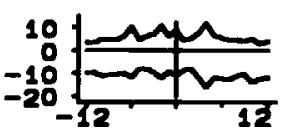

C/acc ( $\%$ GDP)

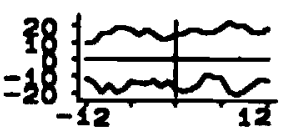

M1 Velocity, chg

Budget ( $x$ GDP)

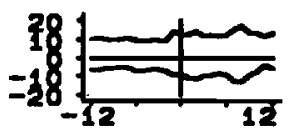

Interest Rate

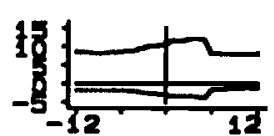

Wage Inflation Unemployment Rate Employment, Chg
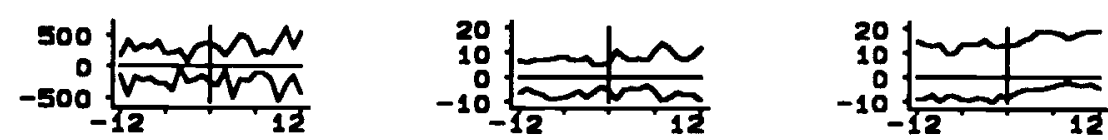

Ind'I Prod'n, Chg Investment, Chg Inventory, Chg Real GDP Growth Nom'l GDP Growth Bands of Four Standard Deviations, Mean-centered

1: Volatility $+/-12$ Quarters Around (33) Flotations 
Domestic Value minus German Value

Industrial Country Panel, 1959-1993. Samples not Comparable.

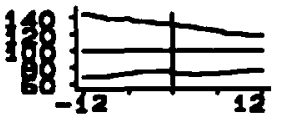

Real Eff FX Rate

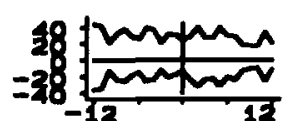

Credit, Chg

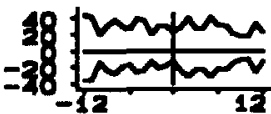

Credit Fund'l, Cho

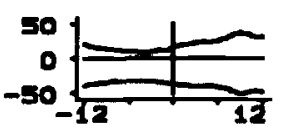

Stock Index

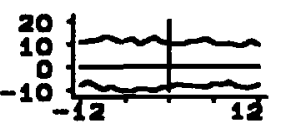

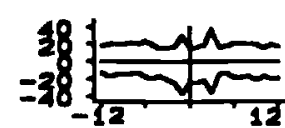

s Exports, Chg

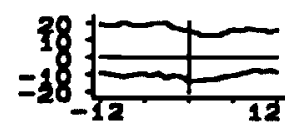

M1. Chg

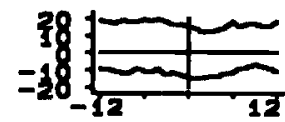

M1 Fund'1, Chg

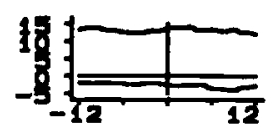

CPI Inflation

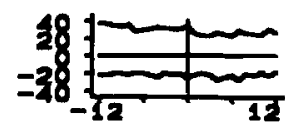

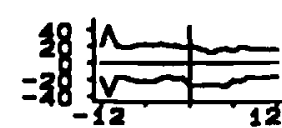

s Imports, chg

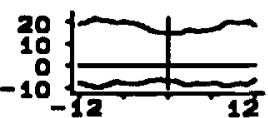

M2, Cho

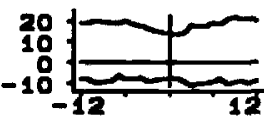

M2 Fund'l, Chg

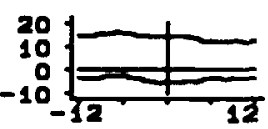

Wage Inflation

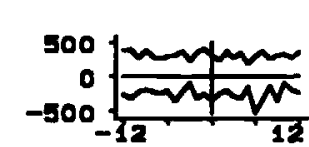

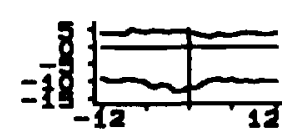

C/acc (X GDP)

FX Reserves, Cho

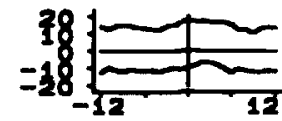

M1 Velocity, Cho

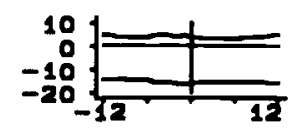

Budget (X GDP)

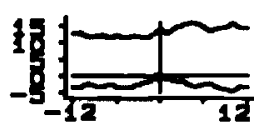

Interest Rate

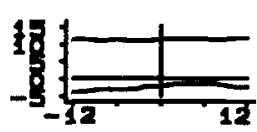

Bond Rate
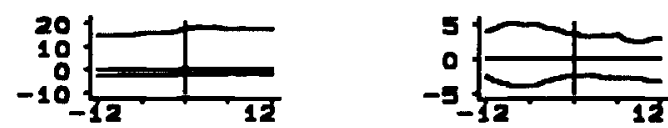

nemployment Rate Employment, Chg
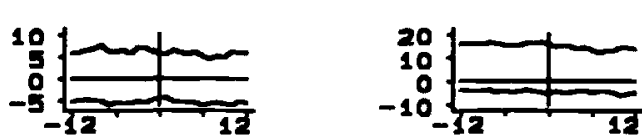

Ind'l Prod'n, Chg Inveetment, Chg Inventory, Chg Aeal GDP Growth Nom'l GDP Growth Bands of Four Standard Deviations, Mean-centered

2: Volatility +/- 12 Quarters Around (B1) Devaluations 